\title{
Overview of surgical techniques in gender-affirming genital surgery
}

\author{
Mang L. Chen ${ }^{1}$, Polina Reyblat ${ }^{2}$, Melissa M. Poh ${ }^{2}$, Amanda C. Chi ${ }^{2}$ \\ ${ }^{1}$ GU Recon, Los Angeles, CA, USA; ${ }^{2}$ Southern California Permanente Medical Group, Los Angeles, CA, USA \\ Contributions: (I) Conception and design: ML Chen, AC Chi; (II) Administrative support: None; (III) Provision of study materials or patients: All \\ authors; (IV) Collection and assembly of data: None; (V) Data analysis and interpretation: None; (VI) Manuscript writing: All authors; (VII) Final \\ approval of manuscript: All authors. \\ Correspondence to: Amanda C. Chi. 6041 Cadillac Ave, Los Angeles, CA 90034, USA. Email: amanda.c.chi@kp.org.
}

\begin{abstract}
Gender related genitourinary surgeries are vitally important in the management of gender dysphoria. Vaginoplasty, metoidioplasty, phalloplasty and their associated surgeries help patients achieve their main goal of aligning their body and mind. These surgeries warrant careful adherence to reconstructive surgical principles as many patients can require corrective surgeries from complications that arise. Perioperative assessment, the surgical techniques employed for vaginoplasty, phalloplasty, metoidioplasty, and their associated procedures are described. The general reconstructive principles for managing complications including urethroplasty to correct urethral bulging, vaginl stenosis, clitoroplasty and labiaplasty after primary vaginoplasty, and urethroplasty for strictures and fistulas, neophallus and neoscrotal reconstruction after phalloplasty are outlined as well.
\end{abstract}

Keywords: Transgender; vaginoplasty; phalloplasty; metoidioplasty

Submitted May 30, 2019. Accepted for publication Jun 20, 2019.

doi: $10.21037 /$ tau.2019.06.19

View this article at: http://dx.doi.org/10.21037/tau.2019.06.19

\section{Introduction}

The rise in social awareness of gender dysphoria has led to an increased recognition of the medical and surgical needs of the transgender population. It is estimated that $0.5-1.3 \%$ of the population in the United States has gender dysphoria (1). Hormone treatment and breast reconstruction for transgender and gender non-conforming (TGNC) individuals has a longer care history than genitourinary surgery, and is therefore more accessible with more providers able to offer these services. Urologic care for gender-related genitourinary surgery (GRGUS), however, remains sparsely available and has only recently gained nationwide traction. The most common surgeries are vaginoplasty for the transfeminine population, and phalloplasty and metoidioplasty for transmasculine patients. Vaginoplasty involves penectomy, orchiectomy, partial urethrectomy, neovaginal canal creation between the rectum and the lower urinary tract, formation of perineogenital complex for patients who desire a functional vaginal canal, labiaplasty, and clitoroplasty. Phalloplasty involves vaginectomy, urethroplasty, neophallus creation, scrotoplasty, perineal reconstruction, and glansplasty. Metoidioplasty is similar to phalloplasty except for the neophallus creation. Each of these primary GRGUSs carries their own unique urologic risks that require reconstructive urologic follow up. Examples of reconstructive procedures after vaginoplasty include urethroplasty to correct urethral bulging, clitoroplasty and labiaplasty. After phalloplasty, urethroplasty for strictures and fistulas, neophallus and neoscrotal reconstruction, and prosthetic surgery may be required. We will review the peri-operative assessment, the surgical techniques employed, and the complications of vaginoplasty, phalloplasty, metoidioplasty, and their associated procedures. Thereafter, the urologic implications and management will be described in detail. 


\section{Transfeminine genitourinary surgery}

\section{Preoperative assessment}

Patients presenting for surgical consultation should satisfy WPATH guidelines by the time of planned genitourinary surgery. Preoperative assessment of the patient also includes discussion of the patient's surgical goals and understanding of the risks associated with surgery. Patients may desire a full depth vaginoplasty, which encompasses bilateral orchiectomy, penile disassembly, creation of neovaginal cavity between the rectum and the urogenital structures (prostate and bladder), labiaplasty, clitoroplasty, and urethral reconstruction. Other patients, such as those with previous perineal surgery or radiation, those who do not wish or cannot physically dilate, or those who do not desire penetrative intercourse may also choose a shallow depth or zero depth vaginoplasty. This includes all of the steps of a full-depth vaginoplasty minus the actual creation of the neovagina. Surgeons should perform a thorough history and physical exam, taking special note of factors that may affect penile skin flap/scrotal skin graft availability and viability, hair removal status, and prior surgical history that may make neovaginal dissection and creation more difficult. The three main techniques are: (I) genital skin flap vaginoplasty; (II) intestinal vaginoplasty; and (III) non-genital skin flap vaginoplasty. The genital skin flap method, specifically, the penile inversion approach, is the most popular technique. Our discussion will focus on evaluating factors most relevant to penile inversion vaginoplasty.

Assessment of the laxity and size of the penile shaft skin and the scrotum can help counsel patients on the potential need for full thickness skin grafts from other donor sites. Of note, the usable length of the penile shaft is limited by the location of the circumcision scar in circumcised individuals. In vaginoplasty techniques supplemented with other tissue flaps, such as peritoneal flaps as described for the Davydov procedure (2), patients may not need additional skin grafts.

Permanent hair removal should be completed in areas that will be used to create the neovagina and introitus. This includes the perineum, penile shaft, central portion of the scrotum, and ring of skin around the base of the penis. Hair growth in the vaginal canal may lead to an increase in discharge, discomfort with dilation or intercourse, unpleasant odor, formation of nests of hair, and concretions. Intraoperative scraping of residual hair follicles has been described, but leads to graft thinning and may increase the risk of graft loss or postoperative canal stenosis. While laser hair removal is better tolerated, it may not be permanent and works best in patients with dark hair and light skin. In our practice, we prefer electrolysis for permanent hair removal. Depilation evaluations are conducted preoperatively to assess adequacy.

Bowel preparation is completed two days prior to surgery to facilitate repair of rectal injury should it occur during the neovaginal canal dissection. Patients should stop the use of nicotine containing products and all inhalational products for at least three months prior to and after surgery to reduce wound healing complications and maximize graft take.

Patients with prior pelvic surgeries in the rectoprostatic plane, such as radical prostatectomy, proctectomy, as well as patients who have had pelvic radiation, should be counseled on the increased difficulty in dissection of the neovaginal canal. This may increase the risk of rectal, bladder, and/or urethral injury, leading to the possibility of urethroneovaginal and/or rectoneovaginal fistula formation. In circumstances where risk of significant complication is high, patients should be well-informed and advised that shallow-depth vaginoplasty may be a good option for a feminine appearing perineogenital complex without potential morbidity associated with creating a neovaginal canal. While prior history of penile urethral stricture may not affect urinary function post vaginoplasty, those with bulbous urethral or more proximal strictures may require additional urethral reconstruction at the time of vaginoplasty.

Estrogen supplementation is stopped two weeks prior to surgical procedure, to help minimize risks contributing to deep venous thrombosis and pulmonary embolism. Preoperative anticoagulation with subcutaneous heparin, intraoperative sequential compression device, as well as perioperative chemical prophylaxis is used.

\section{Operative principles in vaginoplasty}

In our penile inversion vaginoplasty, we use a superiorly based penile skin flap supplemented with a scrotal skin graft to line the neovagina (Figure 1). The patient is placed in dorsal lithotomy position. The scrotal skin is harvested and thinned to make a full thickness graft. It will be tubularized around a dilator and anastomosed to the penile skin that is inverted. A small posteriorly based perineal flap (Figure $2 A, B, C$ ) is made to create a high posterior fourchette and decrease the risk of introital stenosis. We then proceed with bilateral orchiectomy, followed by dissection of the neovaginal canal.

Lone Star elastic stays (Cooper Surgical, Trumbull, CT, 
USA) are used to maintain exposure in the perineum. The bulbospongiosus muscles are kept in situ until dissection of the canal is complete. Bulbospongiosus muscle protects the corpus spongiosum from retraction injury during this portion of the dissection and can be used as a muscle flap in the event of a rectal injury. We use a Lowsley (V. Mueller \& Co., Chicago, IL, USA) retractor placed into the bladder to aid in identification of the plane between the prostate and the rectum by rotating the prostate and bladder anteriorly and into the surgical field. A combination of sharp dissection

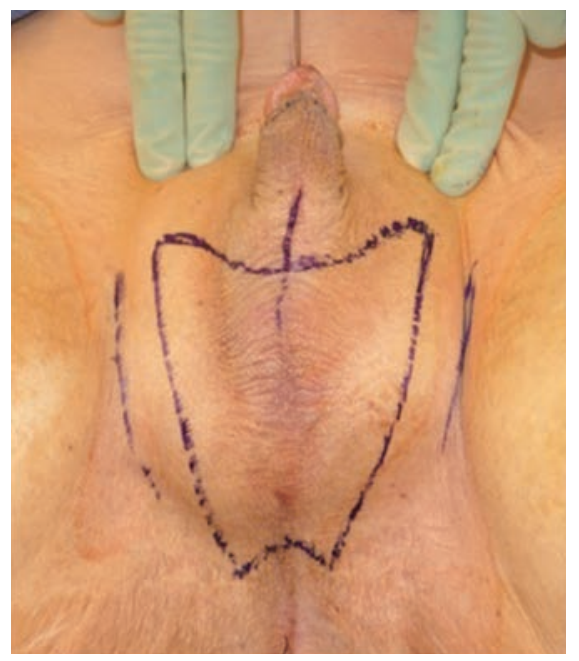

Figure 1 Skin marking depicting scrotal skin graft used penile inversion vaginoplasty. and electrocautery is carried through the central tendon and around the curve of the bulbous corpora cavernosum. Following the course of the urethra and the outline of posterior prostate, dissection is carried along Denonvilliers' fascia. Once the correct plane has been established, the neovaginal canal can be gently and bluntly opened by using two Heaney retractors anteriorly and posteriorly. A rectal exam is performed intermittently throughout the dissection of the neovaginal canal to confirm integrity of the rectal wall.

Wide dissection of the pelvic floor muscles laterally is important in order to develop adequate width of the introitus. Failure to divide the anterior levator ani muscles may lead to difficulty in dilation and a narrow introitus. This dissection is best performed with slow and meticulous cautery. Bleeding from branches of the internal pudendal artery typically occurs, requiring suture ligation of these vessels in addition to electrocautery. In our experience, hemostasis is best controlled with 2-0 Vicryl on UR-6 needles, which allow placement of sutures at these steep angles. Hemostasis of the neovaginal space is critical prior to placement of the penile skin flap/scrotal skin graft complex into the canal. While the packing placed into neovagina will aid with tight apposition between the skin graft and surrounding tissue bed in the retroprostatic space, formation of a hematoma in the neovaginal canal can prevent take of the skin flap and graft, and lead to vaginal prolapse or graft necrosis. In the long term, graft loss can lead to the development of granulation tissue and possible vaginal stenosis.
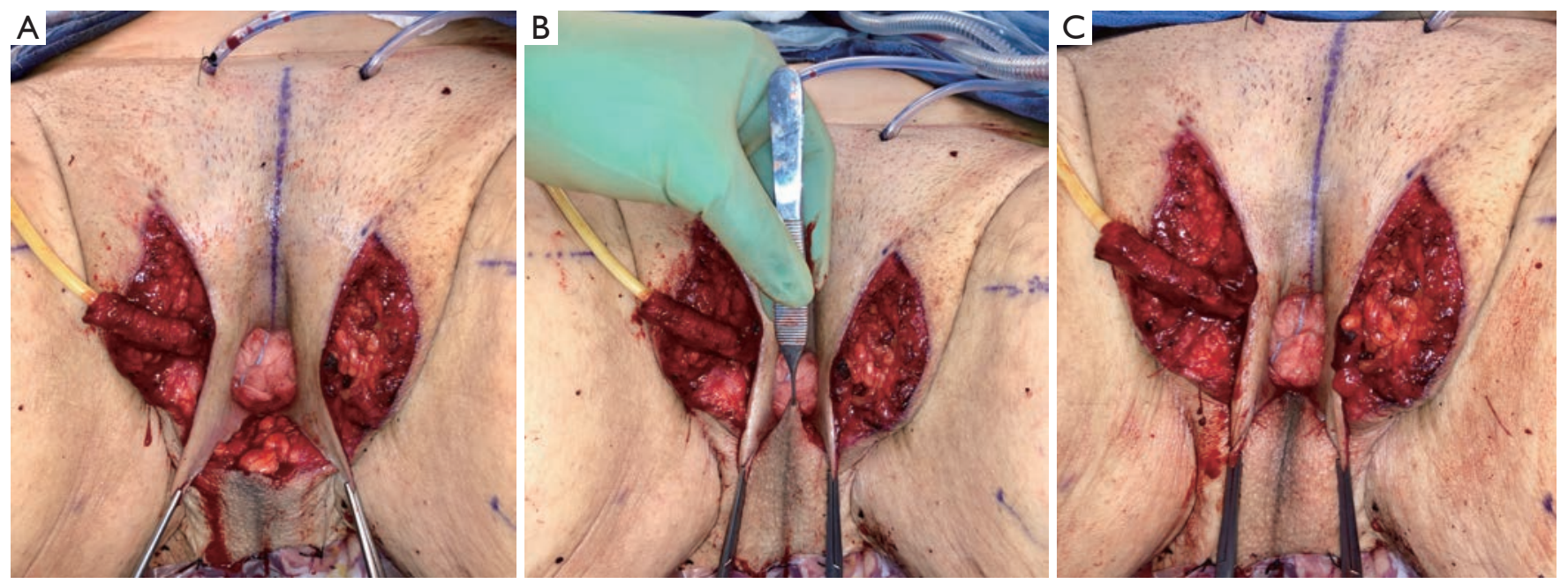

Figure 2 Creation of a posteriorly based perineal flap. (A) Midline incision made on posterior aspect of inverted penile skin flap; (B) small posteriorly based perineal flap; (C) perineal flap advanced into posterior fourchette. 
The phallus is then disassembled. Bulbospongiosus is removed completely to decrease bulk in this area if not needed as a local flap for rectal repair. The penis is degloved proximal to the corona, taking care to leave as much dartos layer with penile skin flap as possible. Corpus spongiosum is then dissected off corpora cavernosa, and the attachment of the corpus spongiosum to the crus of the corpora cavernosa should be separated so the urethra can point in a downward position when the patient sits to urinate. Circumventing this step can result in an anteriorly directed stream, where the patient would complain of messy and non-hygienic voiding.

The urethra is transected below the glans and kept temporarily long. The final length is determined prior to maturing urethral neomeatus. Bilateral ventral corporal cavernosal tissue is removed as proximally as possible. Tunica albuginea of the remaining crura of the cavernosum

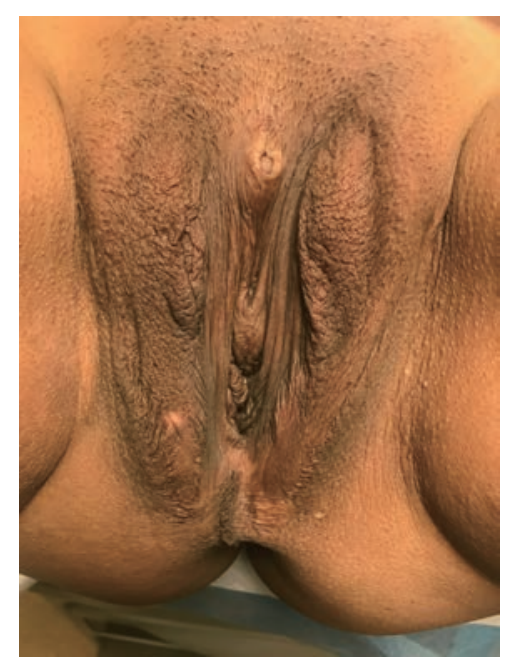

Figure 3 Urethral bulge that protruding into anterior vagina.
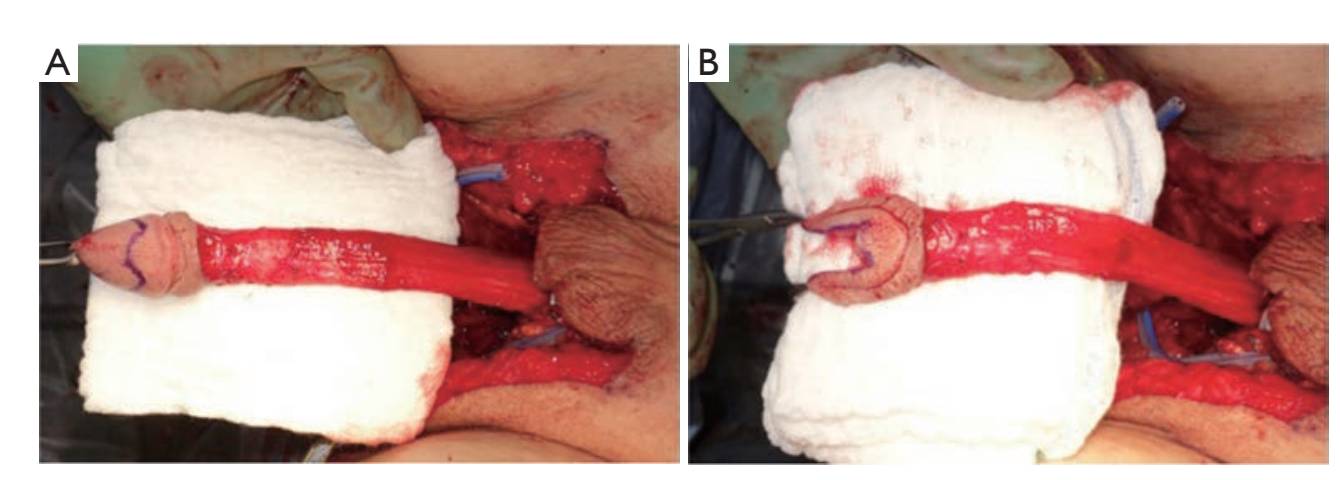

Figure 4 Glans is rearranged to construct the neoclitoris.

is closed with running sutures for hemostasis. The spongy tissue is excised off the remaining corpora cavernosum for both bulk reduction and hemostasis. The remaining dorsal strip of tunica albuginea carrying neurovascular bundle and connected to the glans is then narrowed with care taken not to damage the bundle. Finally, the redundant corpus spongiosum tissue at bulbous urethra should be tapered. If not adequately tapered, a periurethral bulge (Figure 3) that protrudes into the distal anterior vaginal canal can present in patients post operatively. Patients describe it as a sensation of engorged erectile tissue around the urethra and vaginal opening, particularly during arousal, causing problems with intercourse, pain, discomfort or dysphoria. The excessive tissue is trimmed parallel to the urethra, as delineated by an indwelling catheter. The edges of the trimmed corpus spongiosum can be closed with 4-0 Vicryl suture.

The mons and the adjacent inferior abdominal wall are elevated in order to achieve a tension-free advancement of the penile skin flap. The glans is trimmed and rearranged into the neoclitoris (Figure 4A,B). The tissue on the deep surface including any remaining distal corpus cavernosal tissue is resected in order to thin out the neoclitoris and reduces bulk and projection of the neoclitoris. The pedicle to the neoclitoris is then folded gently on itself (Figure 5) to set the neoclitoris at the level of the adductor longus tendons. The anatomical positioning of the neoclitoris provides a set point for the position of the urethral neomeatus and neovaginal introitus. If the neomeatus is positioned too superiorly, the neoclitoris tends to protrude and can become easily irritated by overlying clothing. The pedicle is secured to the fascia on the mons with only two laterally placed sutures at the edge of the pedicle to minimize injury to the neurovascular bundle. It is vital to 


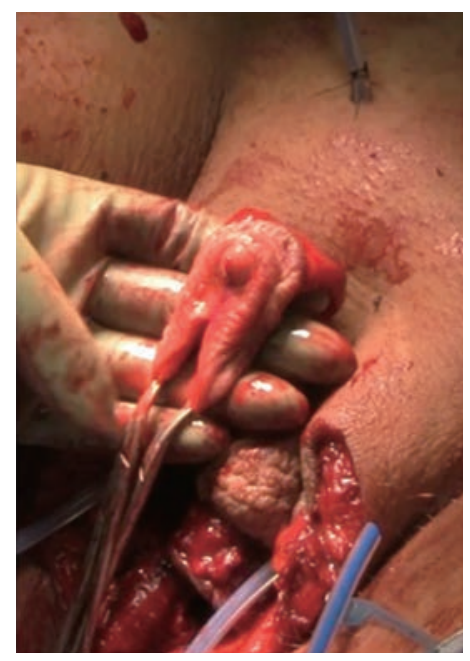

Figure 5 Pedicle of the neoclitoris is folded gently on itself.

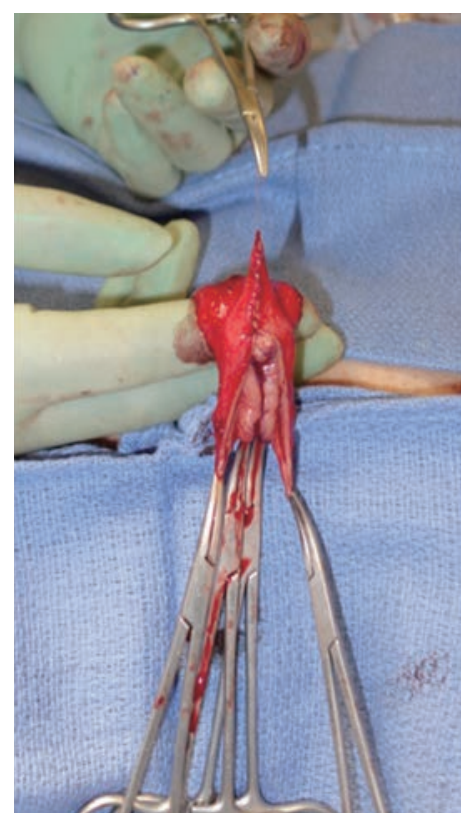

Figure 6 Clitoral hood is formed by folding the prepuce skin.

ensure the pedicle follows a gentle curve and that there is no tension on the pedicle once the neoclitoris is set anterior to the urethra. We create the clitoral hood by folding the prepuce skin over the neoclitoris and closing it at the level of the neoclitoral body (Figure 6).

The penile skin flap with scrotal skin graft cap is then inverted and tunneled into the neovaginal canal and tightly packed with lubricated vaginal packing. Meticulous hemostasis in the neovaginal canal prior to placement of

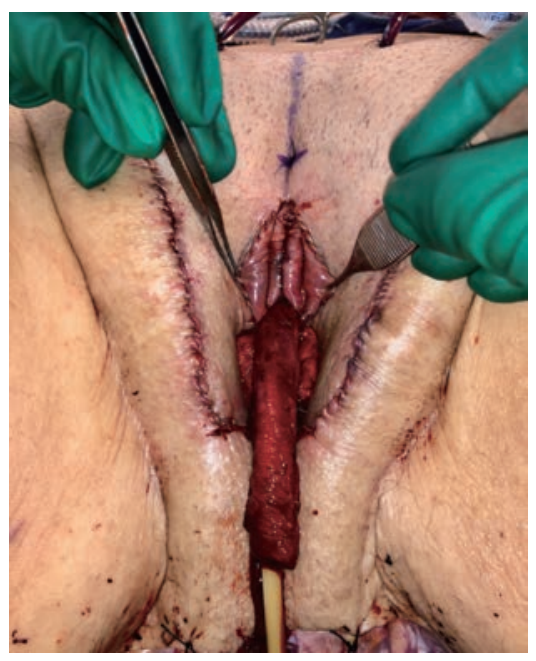

Figure 7 Position of the neomeatus relative to the neoclitoris, prior to transection of the urethra.

graft is critical to prevent hematoma formation. Hematoma inside the neovaginal canal affects graft take and can lead to neovaginal prolapse or graft loss. Some surgeons choose to place colpopexy-type suture with the aim to prevent potential neovaginal prolapse; this has not been necessary in our experience. A posterior midline incision is made into the inverted penile skin flap to reduce the tension of the advanced flap. The perineal flap is then inset into this opening and tacked carefully to the muscle at the posterior introitus to lessen the anterior retraction of the flap. Drains are placed under the mons region and the labia majora.

After completion of clitoroplasty and labiaplasty, and the position of the neomeatus has been determined, the urethra is trimmed to the appropriate length. In our practice, the distance between the neoclitoris and urethral meatus is spanned by the lateral limbs of the rearranged glans, rather than with dorsal urethral plate (Figure 7). The central portion of the neoclitoris is sewn together leaving the two lateral limbs open so that the urethra can be inset in between these two limbs. The amount of closure depends on the distance desired between the neoclitoral body and the urethra and the size of the glans. In our experience, the urethra will retract slightly with healing. We suspect that excessive retraction and resultant tension may contribute to the development of meatal stenosis. Therefore, the urethra should be transected just distal to surrounding tissue and spatulated at ventrally. Eversion of urethral mucosa and hemostasis is obtained with running 5-0 Maxon. The urethral meatus is then matured with interrupted 4-0 Vicryl. 

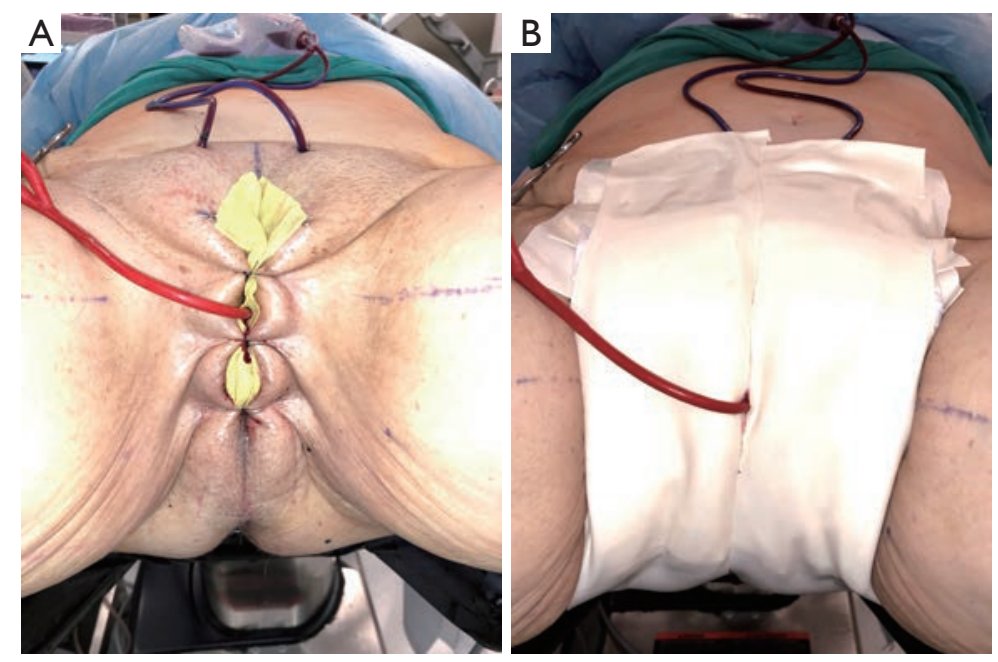

Figure 8 Post vaginoplasty pressure dressing. (A) Labia majora sewn together to keep vaginal packing in place; (B) pressure dressing.

A foley catheter is maintained until vaginal packing has been removed.

Immediately postoperatively, the labia majora are sewn together to maintain vaginal packing in place. A pressure dressing is applied over bilateral labial and mons; it is kept in place for 48 to 72 hours (Figure 8A,B).

\section{Reconstruction after vaginoplasty}

\section{Vaginal stenosis}

Neovaginal stenosis is a complication that may be caused by one or a combination of factors: poor adherence to the dilation protocol; difficulty/pain with dilation; progressive scar contracture associated with lack of graft take and/ or granulation tissue development. Pain and pelvic floor dysfunction could be due to insufficient dissection of the levator ani complex at the time of the neovaginal canal formation. In addition, preexisting pelvic floor dysfunction can contribute to difficulty in relaxing pelvic floor muscles during dilation. In a recent retrospective review by Jiang et al., $42 \%$ of patients undergoing vaginoplasty had preexisting pelvic floor dysfunction that were identified preoperatively (3). Timely intervention with pelvic floor physical therapy demonstrated improvement in pelvic floor function leading to successful dilation (3). In patients who experience pain with dilation due to granulation tissue, therapy should focus on treatment of granulation tissue while maintaining a consistent dilation schedule.

Neovaginal stenosis may be divided into introital or canal stenosis. Introital stenosis-or narrowing of the neovaginal opening — can lead to loss of depth of the canal due to difficulty with complete dilation. Symptomatic narrowing of the introitus was reported in $12 \%$ (4.2-15\%) of the cases (4) and may be managed by stricturoplasty with local advancement flaps. In some instances, additional skin grafts may be required to enlarge the circumference of the introitus. Neovaginal canal stenosis may occur in $7 \%$ $(1-12 \%)$ of patients $(3,4)$, and management is similar to introital stenosis except for the higher likelihood of needing epidermal autografts after incision of the stenotic portion of the canal. On occasion, gastrointestinal or peritoneal flaps are required. We must emphasize that reported neovaginal stenosis rates are likely under-reported given that many patients are geographically distant from where their surgeries were performed. Many patients may also lack resources or interest in pursuing further intervention.

Neovaginal canal stenosis requires surgical intervention for re-establishment of the full-length canal. Pedicled intestinal segment and peritoneal flap vaginoplasty (5) have become the two most commonly employed options which avoid external scars and use of skin grafts elsewhere on the body. It is well-established that repeat dissection in the rectoprostatic space, particularly from a perineal approach, carries an increased risk of rectal and bladder injury when compared to primary vaginoplasty (6). Secondary intestinal vaginoplasty has higher rates of revision surgeries $[79 \%$ (6) vs. $21.7 \%(7)]$ and has additional risks and potential complications associated with intra-abdominal surgery. Examples include bowel obstruction, anastomotic leak, diversion colitis, and mucocele due to a closed blind 


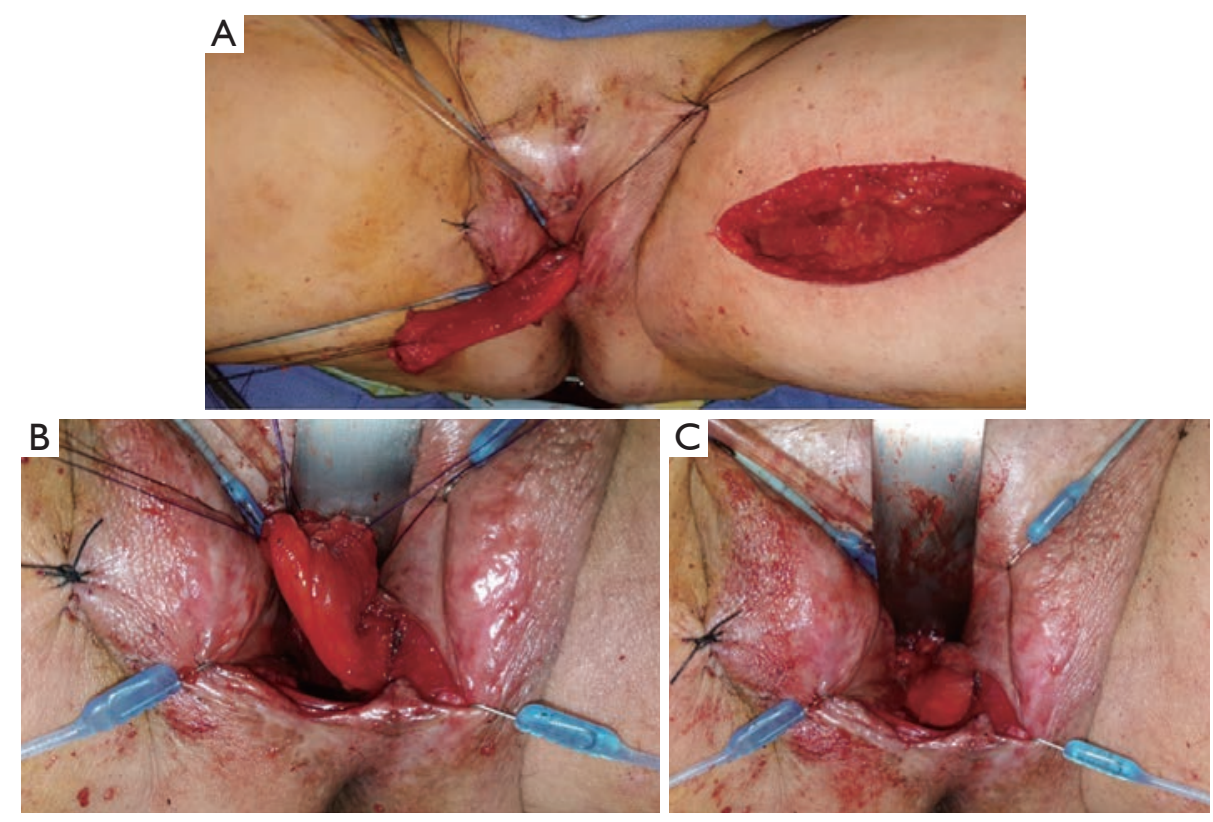

Figure 9 Transvaginal repair of rectoneovaginal fistula with gracilis interposition flap. (A) Gracilis interposition flap; (B,C) insetting the gracilis flap.

loop of intestine if stenosis reoccurs. In some cases, the intestinal neovagina had to be removed due to infection leading to necrosis of the colonic segment and recurrent stenosis related to ischemia (6). Peritoneal flap vaginoplasty has emerged as a safer option for these challenging cases. This approach utilizes a combined transabdominal and perineal approach similar to the one described by Davydov in 1969 (2) as a treatment for vaginal agenesis. Similar to intestinal vaginoplasty, peritoneal flap vaginoplasty may also play a significant role as a primary surgery, particularly for patients with limited amounts of genital skin (5).

\section{Rectoneovaginal fistula}

A rectoneovaginal fistula is a devastating complication that can occur after an unrecognized rectal injury or after a failed repair of a recognized rectal injury. In a retrospective review of records of 1,082 transgender women by van der Sluis et al. (6), 8 of 997 (0.8\%) patients who underwent primary vaginoplasty developed rectoneovaginal fistuli. The rate of fistula formation was higher, at $6.25 \%$, in secondary vaginoplasties. Out of 21 patients who had rectal injuries that were repaired intraoperatively, 4 (19\%) still developed rectoneovaginal fistula shortly after the operation, implying immediate repair is helpful for many but patients will need to be monitored closely for fistula recurrence. Others fistuli are thought to be due to unrecognized rectal injury at the time of dissection (6). These can initially be managed with low residue diets. Unfortunately, this rarely works and most patients require surgical repair of the fistula employing various interposition grafts or flaps (6).

Diagnosis of the rectoneovaginal fistula requires clinical suspicion and congruent physical exam findings. Patients typically will describe stool or gas emanating from the neovaginal canal. Presence of fecal matter in the neovaginal vault should prompt neovaginal speculum exam and rectal exam in order to confirm the presence of fistula. Imaging studies such as gastrografin enema, endoscopy, CT, or MRI, can support the diagnosis, but are rarely necessary. Similar to treatment of any rectovaginal fistula, fecal diversion with temporary colostomy is typically necessary to optimize chance of resolution. Failure of resolution of fistula with conservative measures requires excision of the fistula and repair of rectal and neovaginal defect with interpositioning local tissue flaps. Patients should be counseled on the potential of neovaginal canal stenosis if neovaginal dilation is interrupted for a prolonged period of time. In the past, patients were instructed to cease dilation to allow the neovaginal canal to close, thus treating the fistula but leading to loss of the neovaginal canal. We have repaired a rectoneovaginal fistula through a transvaginal approach and using gracilis flap interposition (Figure 9A,B,C). The repair was completed 3 months after the patient underwent 


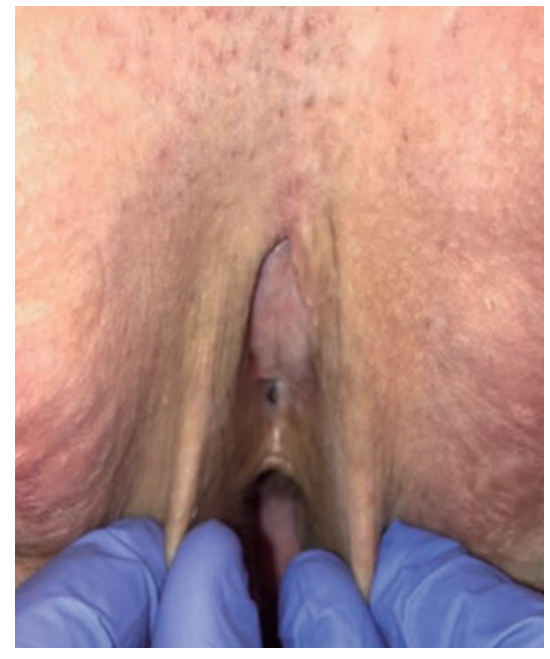

Figure 10 Pinpoint neomeatus.

diverting colostomy, corresponding to 6 months after her initial vaginoplasty. We re-established a dilation schedule performed by the surgeon at 1 month post repair and then allowed the patient to resume dilation on her own at 3 months post repair. In this manner, the patient's width and depth of her neovaginal canal was preserved.

\section{Urethroneovaginal fistula}

Reported incidence for urethroneovaginal fistula range from $0.8-3.9 \%(5,8-10)$. This likely occurs due to unrecognized urethral injury or breakdown of a repaired urethral injury. In patients with a distal urethroneovaginal fistula, one can consider excising the distal bridge of tissue, resulting in a more recessed urethral meatus. In the case of a more proximal fistula, the fistula can be repaired transvaginally to close the neovaginal defect and urethral defect with local interpositioning flaps.

\section{Urethral stricture and urethral malposition}

The most likely location of a urethral stricture post vaginoplasty is at the urethral meatus. The reported incidence of meatal stenosis varies widely, with most authors noting 1-6\% $(9,11,12)$ and one group noting $40 \%(10)$. The rates of meatal stenosis in vaginoplasty techniques that transect the urethra at the meatus versus those that preserve the posterior urethral plate to span between the neoclitoris and urethral meatus have not been parsed out. Complaints of new onset obstructive urinary symptoms such as weak stream or feeling of incomplete emptying should raise suspicion for urethral stricture disease, particularly in those patients who did not have these symptoms prior to vaginoplasty. Patients with urethral strictures can also present with urinary retention and frequent urinary tract infections. Meatal stenosis can usually be diagnosed on physical exam (Figure 10). In patients who are not in urinary retention and maintain normal renal function, we prefer to avoid dilation of the stenotic segment and plan for definitive surgical reconstruction. Dilation will alter anatomy, making it more difficult for the surgeon to ensure that the entire narrowed segment has been excised. During urethroplasty, a small caliber catheter is placed via the stenotic meatus to help delineate urethra. A circumscribing incision is made and corpus spongiosum and urethra are dissected sharply away from surrounding tissue. Care is taken to develop the plane along the corpus spongiosum to maintain blood supply to the urethra and adjacent skin flap. The stenotic segment is transected sharply and urethral edge is spatulated ventrally to ensure a large caliber urethral meatus. We place a running suture circumferentially to evert urethral mucosa and for hemostasis. A V flap is created from the anterior neovaginal wall and advanced into the posteriorly spatulated portion of the urethra. Urethral meatus is then matured with interrupted 4-0 Vicryl sutures. A catheter remains in place for $5-7$ days postoperatively.

The urethral meatus can also be anteriorly malpositioned, leading to deviation of the urine stream in a forward direction when the patient sits to void. This issue frequently presents as a complaint of urine spraying over the edge of the toilet seat, a need to bend the torso forward, or the use a deflective device (e.g., towel) to direct the urine stream downwards. This anterior urethral angle can be corrected by an approach similar to the one described above. In some instances where the attachment of the corpus spongiosum to the crus of the corpora cavernosum was not dissected adequately at the time of the initial operation, more significant periurethral dissection is needed to free up the urethra. Once the urethra has been mobilized adequately to allow it to drop into a position suitable to generate a downward stream, the meatus can be matured as described above. The skin or tissue anterior to the new meatus position has to be closed to compensate for the change urethral position.

\section{Urethral bulb bulge}

A periurethral bulge that protrudes into the distal anterior vaginal canal can present in patients when there is inadequate tapering of corpus spongiosum tissue at bulbous urethra at the time of the vaginoplasty. Patients describe 
it as a sensation of engorged erectile tissue around the urethra and vaginal opening, particularly during arousal, causing problems with intercourse, pain, discomfort or dysphoria. In addition to inadequately tapered corpus spongiosum, the bulge can also be due to incompletely resected bulbospongiosus muscle. Correction of the bulge can be achieved transvaginally, typically with a incision through the penile skin flap that overlies the urethra. The skin flaps are raised and dissection is carried more deeply to expose any remaining bulbospongiosus muscle, which should be excised completely. If there is excessive corpus spongiosum, an indwelling catheter should be placed to delineate the course of the urethra and the ventral aspect of the spongiosum can be tapered to parallel the urethra. The edges of the trimmed corpus spongiosum can be closed with 4-0 Vicryl. In our practice, we maintain vaginal packing and urethral catheter for approximately 5 days in patients with large anterior neovaginal wall incisions to help with adherence of the overlying penile skin flap. If needed, this intervention can be combined with urethral repositioning, labiaplasty, clitoroplasty, or other cosmetic revisions of the perineogenital complex (13).

\section{Clitoral exposure/cosmesis}

Requests for revision due to external genitalia cosmetic appearance are common and generally not considered as a complication. Rate of revision of the perineogenital complex ranges from $25 \%$ to $50 \%(4,14,15)$. These revisions can include additional clitoral coverage by reconstruction of clitoral hood, formation of more defined labia minora, or reduction of labia majora. Timing of revisions should be at least three months from the date of the original surgery to allow for tissues to settle and edema to resolve. In some cases, the posterior fourchette forms a ridge making dilation and intercourse more difficult. This ridge can be revised by readvancing the perineal flap. Clitoroplasty and labiaplasty can be completed as an outpatient surgery and can be combined with revision of urethral meatus or an urethral bulb bulge.

Penile inversion vaginoplasty provides a safe and effective technique in appropriately selected patients to achieve the goals of constructing a functional neovaginal and a feminine-appearing perineogenital complex. Post vaginoplasty patients can presents with a variety of complications ranging from minor and non-operative to those that may require multiple surgical interventions. Thorough preoperative discussions with the patient and even supporting friends and family are extremely important to ensure patients' understanding of the possible short term and long term complications related to this procedure. Broadening medical school and post-graduate curriculum to improve understanding of gender affirming surgical procedures and related anatomy can strength the ability of healthcare providers to provide care for these patients.

\section{Transmasculine genitourinary surgery}

\section{Preoperative assessment}

By the time patients schedule their consultation, many will have already been on hormone therapy for over 1 year and will have established mental and primary health care. Many will also have had double mastectomy and hysterectomy. Patients want to explore their options for GRGUS, which for transmasculine individuals, includes metoidioplasty and phalloplasty, with variable desires for vaginectomy, scrotoplasty, and urethroplasty. Most patients will want all of these procedures; some will want to exclude part of the genitourinary reconstruction for individualized reasons. For example, some patients do not want urethroplasty to avoid the risks of urethral reconstruction, while others avoid vaginectomy. During the history portion of the consultation, ascertainment of the patient's surgical goals is vital to determining which surgery is most appropriate. Patients opting for metoidioplasty generally do not want donor site morbidity and accept a small phallus; patients seeking phalloplasty want a larger and physiologic appearing phallus. For patients whose primary goal is standing micturition, phalloplasty with full length urethroplasty is the more appropriate choice, although clitoral enlargement from hormone therapy may allow thin patients with minimal surrounding genital tissue to void standing after metoidioplasty with urethral lengthening.

As with all surgeries, a thorough history and physical is important. A history of hypertrophic scarring or keloids negatively impacts postoperative complicationsspecifically, urethral strictures. Smoking tobacco, use of nicotine products, or inhalational products of any kind increases wound and other perioperative complications (16-19) to the point where surgery may be cancelled if there is evidence of smoking within 3 months of surgery. Diseases treated with immunotherapy such as steroids may also affect wound healing and are strong contraindications to surgical therapy. Obesity with specific adipose distribution to the pannus or mons pubis and thighs may also prevent safe surgery and at the minimum, negatively impact overall aesthetics and function. A suggested body mass index (BMI) 

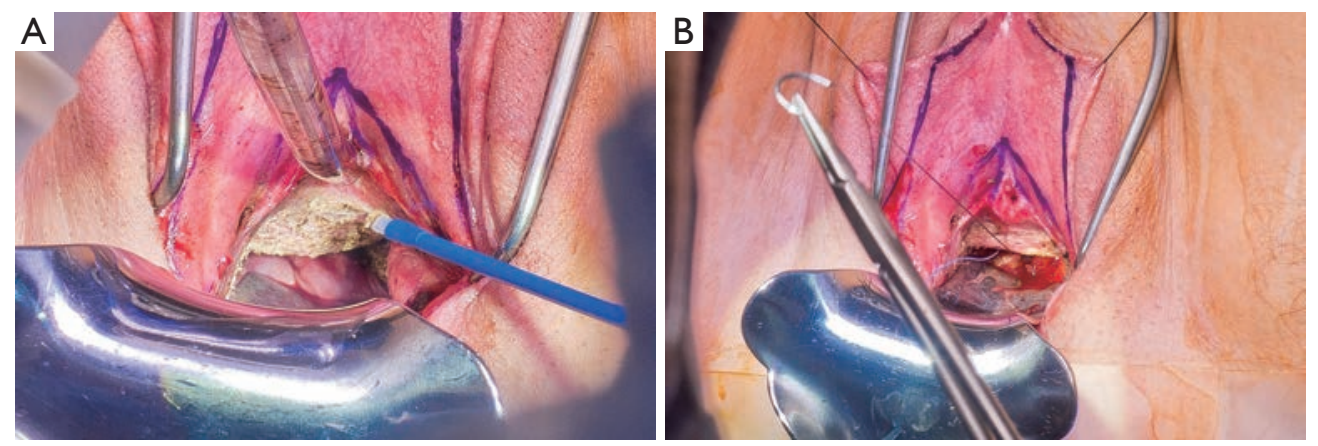

Figure 11 Vaginectomy. (A) After distal sharp mucosal excision, the remainder of the vaginal mucosa is fulgurated; (B) colpocleisis is carried out with thick polydioxanone suture.

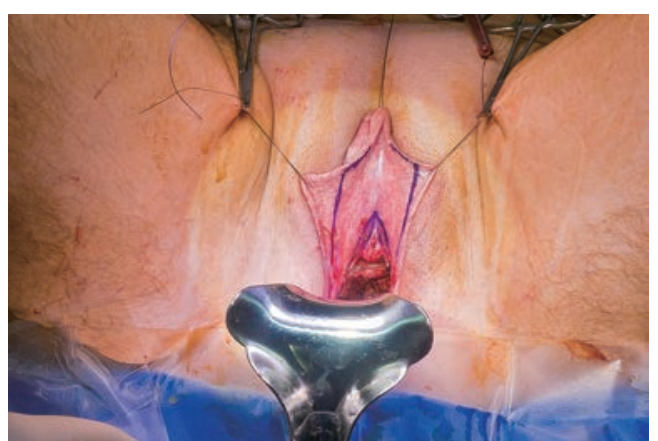

Figure 12 Markings demonstrate tissue used for pars fixa urethroplasty.

cutoff is $35 \mathrm{~kg} / \mathrm{m}^{2}$ for patients desiring radial forearm free flap (RFFF) phalloplasty; ideal body weight is suggested for patients interested in metoidioplasty and anterolateral thigh (ALT) phalloplasty. Despite these guiding principles, BMI alone is a poor indicator for metoidioplasty and ALT phalloplasty candidacy. Physical exam assessment of the surgical sites offers far more accurate predictions of postoperative aesthetics and function.

\section{Metoidioplasty}

Patients desiring metoidioplasty want masculine-appearing genitalia without the morbidity associated with a donor site. This procedure involves chordee release with or without vaginectomy, urethroplasty, scrotoplasty, and perineal reconstruction. A simple metoidioplasty is chordee release, neurovascular pedicle reposition, and ventral phallus skin closure. A full metoidioplasty, in contrast, includes simple metoidioplasty procedures with vaginectomy, scrotoplasty, and urethroplasty. The ideal candidate for metoidioplasty is a thin, healthy patient with minimal surrounding genital tissue and pronounced clitoral enlargement from hormone therapy. The surgical technique employed for patients wanting a full metoidioplasty starts first with vaginectomy. Vaginectomy requires the excision and/or destruction of the vaginal mucosa, followed by a colpocleisis to obliterate the canal (Figure 11A,B). Thick polydioxanone (PDS) suture is used during vaginectomy to decrease the risk of urethral pseudodiverticulum formation at the native urethral anastomotic site. Care is taken to preserve neighboring labia minora tissue as this is used to lengthen the urethra from the native urethral meatus to the glans clitoris (Figure 12). Our urethroplasty technique is modeled after the "ring" flap metoidioplasty first described by Takamatsu (20). During dissection of the ring flap, the chordee is released via transection of the ventral attachments down to the corporal bodies of the clitoris, creating a gap between the base of the clitoris and the urethral meatus. The peri-urethral fornices flanking the urethral meatus are excised (Figure 13A,B) and the inferior portion of the ring flap is divided and then sewn to the dorsal aspect of the native urethral meatus, filling the gap (Figure $14 A, B$ ). The dorsal urethral plate is sewn in several layers, with the first layer securing the submucosal flap tissue to the tissue surrounding the corpora cavernosa (Figure 15). Further urethral reconstruction around the meatus is completed, followed by ventral closure and tubularization of the urethra to the glans clitoris (Figure 16). At the native urethral meatus, the ventral anastomosis with the ring flap will often have excess tissue that can be deepithelialized and used to directly cover the urethral suture line at this location (Figure 17). Excess labia minora skin is then similarly de-epithelialized, creating a subepithelial vascular layer that can be used to cover the urethral suture line (Figure 18). The remaining labia minora skin is then 

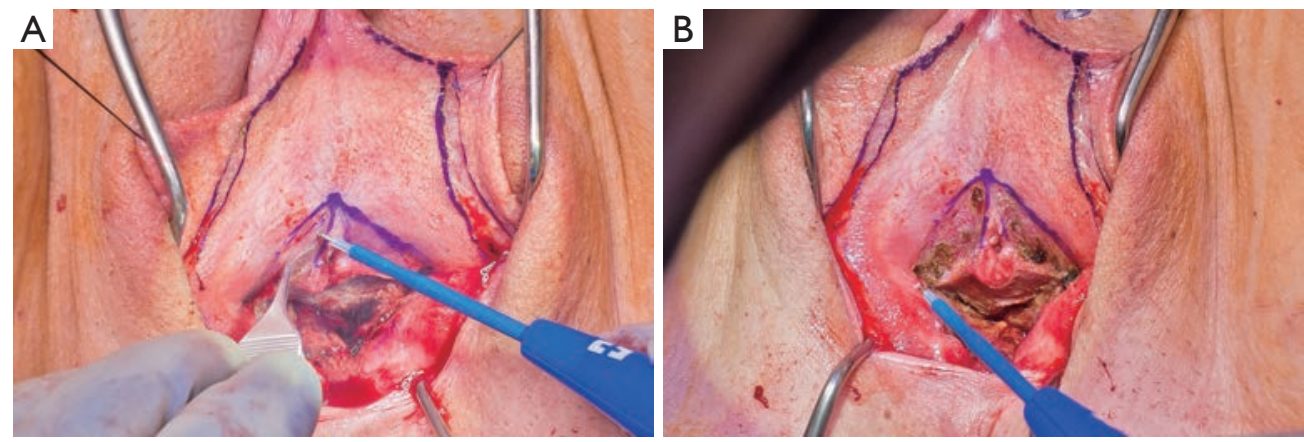

Figure 13 Creation of smooth dorsal urethral plate. (A) There are indentations of mucosa flanking the native urethral meatus-the periurethral fornices; (B) the fornices are demucosalized.
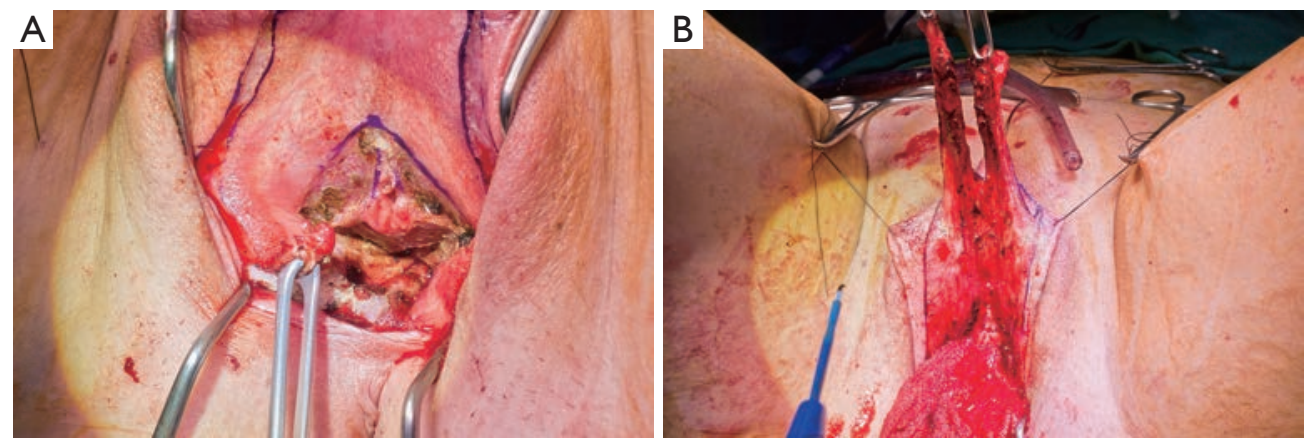

Figure 14 Flap harvest for urethral lengthening. (A) The inferior aspect of the "ring" flap is divided to facilitate flap harvest; (B) labia minora flaps are elevated.

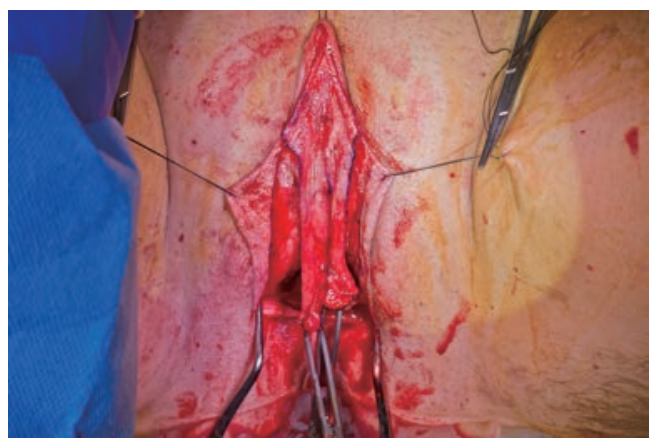

Figure 15 The dorsal urethral plate is created by bringing both parts of the original ring to the midline between the urethral meatus and the inferior aspect of the clitoris after chordee release.

closed ventrally to create a cylindrical phallus. The inferior aspect of the labia majora is then incised via a " $U$ " shaped incision to create flaps that are lifted, rotated and sewn to create a pouch like scrotum just inferior to the base of the phallus (Figure 19). The perineal wound is then

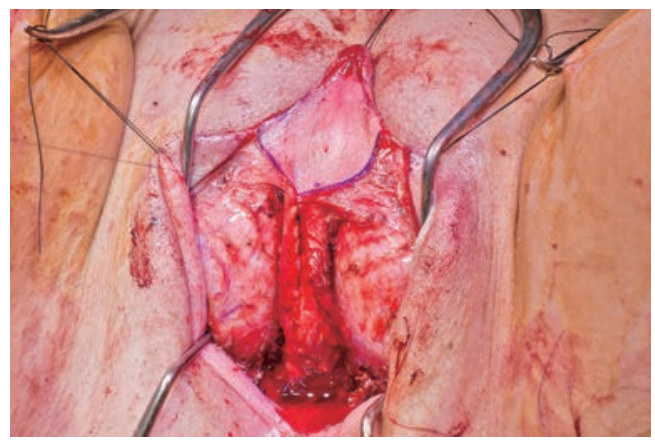

Figure 16 Pars fixa urethroplasty is completed with ventral closure.

closed with several layers of absorbable suture. We place a suprapubic (SP) tube that remains for 2-3 weeks. We close the urethra around a Coude catheter that is removed immediately postoperatively to avoid the risk of catheter related traumatic hypospadias. There are numerous other metoidioplasty techniques described (21-26), but we favor 


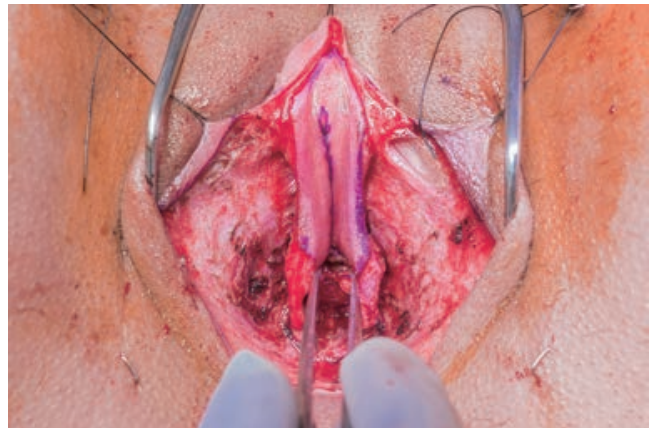

Figure 17 De-epithelialized portions of the labia minora flaps are preserved and used as additional coverage over the native urethralto-ring flap anastomosis.

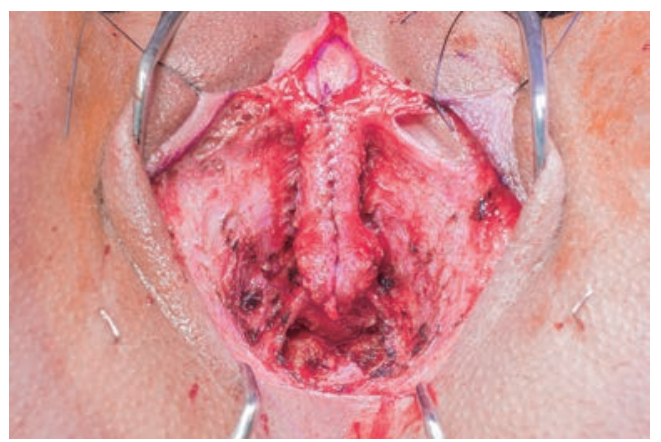

Figure 18 Vascular de-epithelialized flaps from the labia minora tissue not used for urethroplasty are preserved for coverage of the pars fixa urethral suture line.

the ring flap technique as it avoids dorsal clitoral dissection, corporal dissection, and urethral grafts.

Patients undergoing metoidioplasty are either discharged home later that day or watched overnight; rarely do patients require longer hospital stays. We advise patients regarding expected phallus swelling and incisional drainage of serosanguinous fluid. They are advised to ambulate slowly but regularly and notify us of any worsening symptoms. At their first postoperative visit one week later, if the phallus swelling is minimal, patients can attempt a voiding trial. If they are able to void reliably well with minimal post void residuals, the SP tube may be removed on their subsequent visit. If there is significant postoperative swelling, a voiding trial is delayed a week. During their voiding trial, if an urethrocutaneous fistula is noted, voiding trial is delayed for an additional week. Most fistulas are small and heal spontaneously with good wound care and nutrition. On rare occasion, fistula repairs are required. The SP tube is

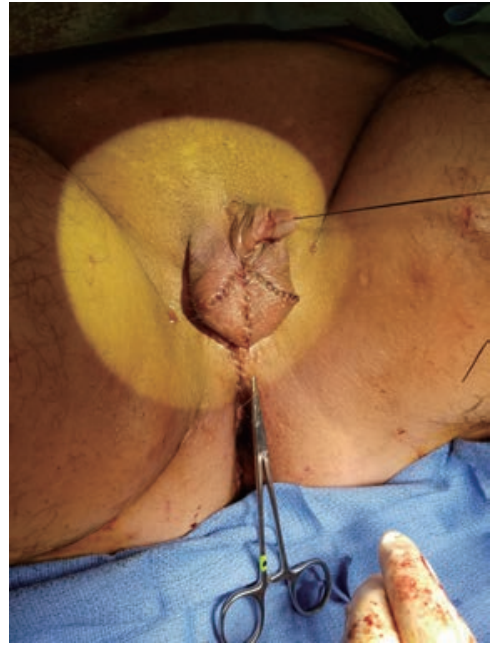

Figure 19 Immediate postoperative photo of patient after metoidioplasty with urethral lengthening, vaginectomy, scrotoplasty, and perineal reconstruction.

removed if the patient can void successfully. Some urologists will perform voiding cystourethrograms (VCUGs) or retrograde urethrograms (RUGs) prior to SP tube removal. Patients are thereafter counseled to watch for obstructive voiding symptoms as about $10 \%$ of patients are prone to stricture formation within the first year (unpublished data). A recent meta-analysis reported metoidioplasty associated urethral complication rate to be around 25\% (27).

About six months after metoidioplasty, some patients will want/need additional procedures, the most common of which is testicular implant insertion with or without monsplasty and upper labia majora fold reduction. This is an outpatient procedure and involves strategic dermatolipectomy of the mons pubis and upper majora tissue to reduce the surrounding tissue around the phallus. Testicular implants can be placed dependently in the scrotum via the labia majora incisions with a pursestring type suture placed superiorly to decrease the risk of cephalad migration of the implant.

For patients who develop strictures or who have fistulas that do not heal, urethral reconstruction is required. Fistula repair involves the excision of the fistula tract followed by multi-layered closure of the site. This can often be completed in a single stage.

\section{Phalloplasty}

Patients seeking phalloplasty often desire a proportionally 


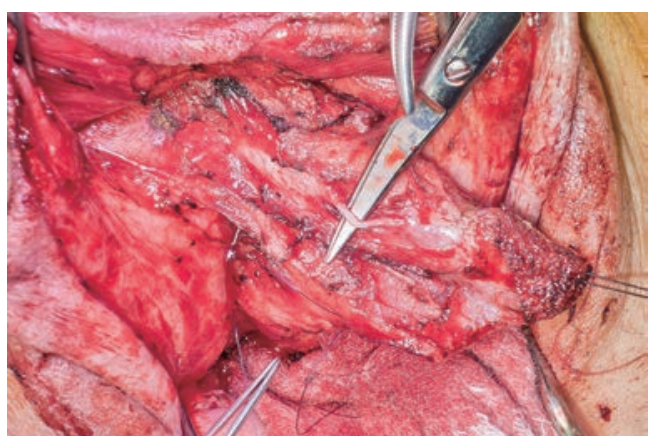

Figure 20 Dorsal nerve dissected free from one side of a deepithelialized clitoris.

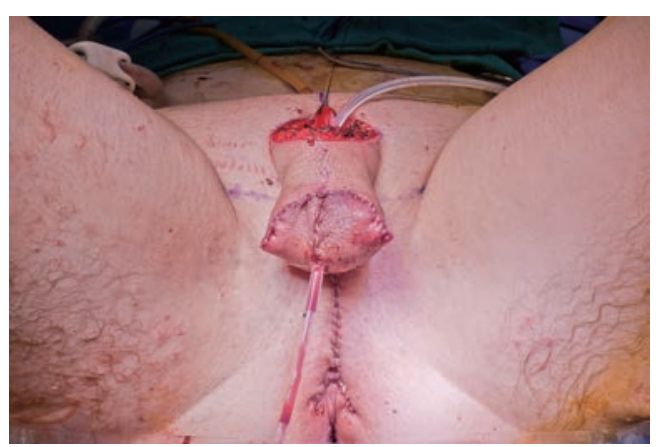

Figure 21 Pouch-like anteriorly positioned scrotum after labia majora flap elevation, rotation, and advancement.

sized phallus with neophallus sensation, the ability to urinate standing, and eventual penetrative sexual function via a penile prosthetic. There are a multitude of techniques and surgical staging options available for phalloplasty (28-52). The most common of technique is a single-stage RFFF phalloplasty with vaginectomy, urethroplasty, scrotoplasty, and perineal reconstruction. The distinct advantages of the radial forearm donor site are the tissue's similarity to genital skin, skin innervation, and a highly reliable neurovascular supply. The major disadvantages are the conspicuous donor site scar and potential for diminished hand function. Patients with an intact palmar arch without prior history of prohibitive radial forearm trauma or intravenous drug use are candidates for the RFFF-widely considered the gold standard for phalloplasty. The second most common donor site is the ALT pedicled or free flap. The advantage of this sensory flap is its more concealable donor site. The main disadvantage is that few patients have the anatomy sufficient for a single staged "tube in tube" ALT phalloplasty as this flap is frequently thicker and will require multiple stages of neophallus and neourethral reconstruction to achieve a functional, more aesthetic and proportionally sized phallus. Other flap options include the musculocutaneous latissimus dorsi free flap, the tibial free flap, and abdominal or groin pedicle flaps $(40,44,53,54)$. These flaps are not offered in our practice given their lack of sensory innervation and their need for staged urethral and neophallus reconstruction. In nearly all RFFF phalloplasty patients, full length urethroplasty and physiologic aesthetics are achievable in the first stage, minimizing the need for multiple stages of neophallus and urethral reconstruction.

The surgical team is composed of microsurgeons and a reconstructive urologist. The patient is positioned in dorsal lithotomy position with the arms perpendicular to the body. The microsurgeons harvest the flap and create the pars pendulans (PP) urethra and neophallus with or without glansplasty depending on the flap used and the patient's specific anatomy. We avoid primary (immediate) glansplasty in ALT flaps and thin RFFFs due to the risk of distal flap necrosis. Thicker RFFF neophalluses accommodate concomitant glansplasty due to a reliable distal flap blood supply from the more abundant adipose tissue. During flap harvesting and neophallus creation, the reconstructive urologist performs the vaginectomy, pars fixa (PF) urethroplasty, scrotoplasty, and perineal reconstruction in a fashion similar to the methods utilized during metoidioplasty. The key differences are the following: clitoris shaft and glans de-epithelialization, dorsal nerve dissection, transposition of the clitoris and PF urethra, and a more extensive scrotoplasty with perineal reconstruction. The clitoris de-epithelialization is required to expose one of the two dominant dorsal nerve branches (Figure 20). This is dissected free and later coapted to the antebrachial cutaneous nerve(s) of the RFFF. The neophallus recipient site in front of the mons pubis is created and the clitoris and PF urethra is translocated to this region. The complex scrotoplasty is then performed by raising labial majora flaps based on the external pudendal blood supply that arises superiorly. The flaps are then lifted and rotated to create a pouch-like scrotum (Figure 21). The perineal reconstruction focuses first on urethral suture line coverage with local flaps. The bulbospongiosus fibromuscular layer covers the $\mathrm{PF}$ urethral suture line directly (Figure 22) followed by perineal fat and inner thigh skin approximation to create a flat, male appearing perineum (Figure 23).

The patient is then repositioned supine upon completion of the phalloplasty, vaginectomy, urethroplasty, 


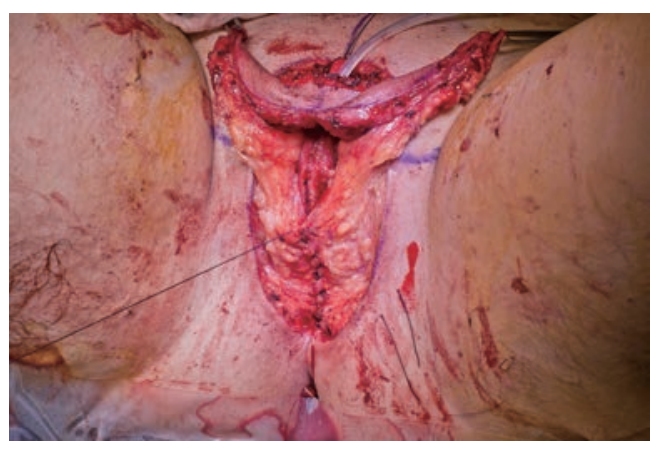

Figure 22 Bulbospongiosus muscle layer is used to cover the proximal pars fixa urethroplasty suture line.

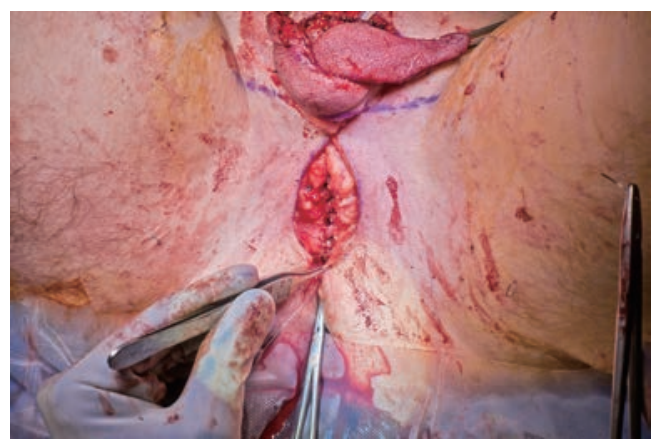

Figure 23 Inner thigh skin is brought towards the midline to complete the perineal reconstruction.

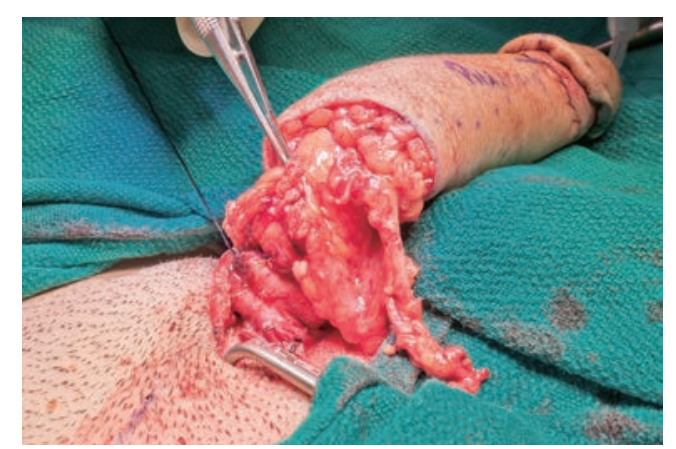

Figure $24 \mathrm{PF}$ and $\mathrm{PP}$ urethral anastomosis. PF, pars fixa; PP, pars pendulans.

scrotoplasty, and perineal reconstruction. Groin dissection of the contralateral femoral vessels is carried out by the microsurgeons. The urologist then passes a Coude catheter into the bladder through the PP and PF urethra. This facilitates the PF and PP urethral anastomosis, which is performed with 5-0 PDS suture (Figure 24). The adipofascial

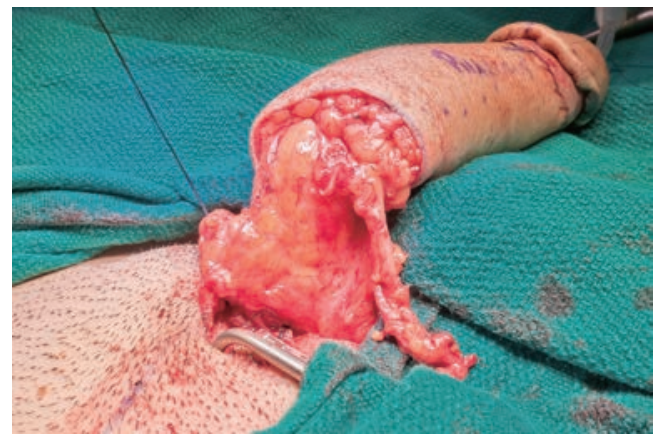

Figure 25 Adipofascial flap from the RFFF covers the PF-PP urethral suture line. RFFF, radial forearm free flap; PF, pars fixa; $\mathrm{PP}$, pars pendulans.

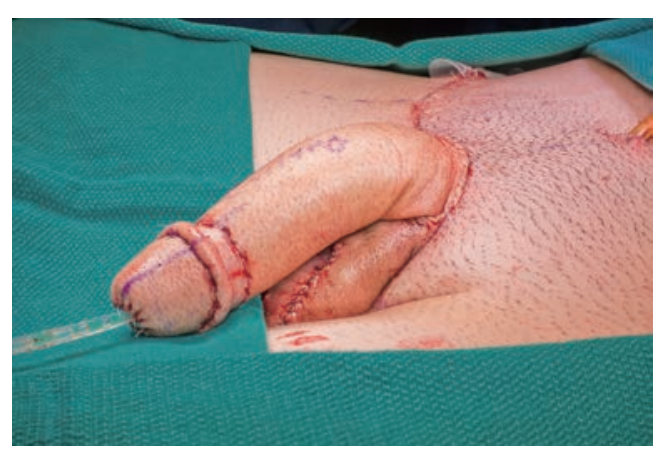

Figure 26 Immediate postoperative appearance of neophallus and scrotum after RFFF phalloplasty, urethroplasty, vaginectomy, scrotoplasty, and perineal reconstruction. RFFF, radial forearm free flap.

extension from the flap covers the urethral suture line at this location (Figure 25). The microsurgeons then coapt the nerves and complete the vascular anastomoses under an operating microscope. The groin wound and donor site are then closed, and split thickness skin grafts (STSG) from the thigh are used to cover the donor site. The phallus is attached to the scrotum and prepubic skin (Figure 26).

Patients are hospitalized for an average of 5 days, with 4 days of bedrest followed by ambulation. The first two days require every 1-2 hour Doppler checks of the phallus. On day 5 , patients are encouraged to walk. If they are walking well with good pain control and gastrointestinal function, they are discharged from the hospital with the urethral and suprapubic catheter. Thereafter, they are followed weekly for 4 weeks. At the first postoperative visit, the urethral catheter is removed. At the second visit, if there is minimal neophallus swelling and the incisions continue to heal well, 
patients are instructed to void with the SP tube clamped. If they are voiding well with minimal post void residuals, the SP catheter is removed at their third postoperative visit. Some urologists will perform VCUGs or RUGs prior to catheter removal.

Complications are common (35,55-60). Fortunately, most are minor, including open wounds and urinary tract or skin infections. These are minimized by instructing patients to ambulate with small steps and minimize large range of motion movements, especially when getting in and out of cars and when sitting from a standing position. Patients are also advised to keep the surgical sites clean and position the phallus about 45 degrees from the plane of their body. Intermediate grade complications often involve the urethra, including fistulas and strictures. About onethird of our RFFF phalloplasty patients develop a fistula and/or stricture, and about half of these patients will require surgical repair 3-6 months after phalloplasty. In our experience, these risks and others are higher in single stage ALT phalloplasties compared to single stage RFFF (citation). Major complications will require surgery during their hospitalization and includes problems such as vascular thrombus formation and/or groin or perineal expanding hematomas. Fortunately, these complications are rare. Patients are at risk for stricture formation for about 1 year (and perhaps longer) after surgery given the natural history of wound maturation (61). We recommend that patients get an uroflow and post void residual determination every 3-4 months postoperatively.

Around 12 months after phalloscrotoplasty or urethroplasty, patients who are stricture recurrence free with neophallus sensation may want penile and testicular implants. Patients who desire further neophallus reconstruction via glans revisions or neophallus size reduction or shaping are encouraged to do so about 6 months prior to implant insertion to minimize risk of penile implant complicationsspecifically, erosion and infection.

\section{Urethral reconstruction after phalloplasty and metoidioplasty}

Urethral strictures and fistulas are relatively common, averaging around $50 \%$ in phalloplasty patients and $25 \%$ in metoidioplasty patients $(20,23-27,55-57,59,62-64)$. In metoidioplasty patients, most fistulas are ventral to the shaft of the phallus and are seen more frequently in patients without abundant labia minora tissue. The second most common location is behind the scrotum at the perineum- scrotum junction. Strictures in metoidioplasty patients are less common, and when present, are usually of the proximal portion of the labia minora urethroplasty-just distal to the native urethral meatus. In phalloplasty patients, the areas at highest risk for urethral fistula or stricture formation are at the PF-PP urethral anastomosis and the neophallus urethral meatus. These are the vascular watershed areas. For patients with prolonged neophallus swelling, fistulas can occur along the ventrum of the shaft several months after phalloplasty. They have a natural history of opening and closing; if they don't close by around 4 months, repair is required.

Fistulas that are small (5 $\mathrm{mm}$ or less) and persist beyond 4 months postoperatively can be repaired primarily. Patients who are at risk of fistula formation often have minimal labia minora tissue, which then leads to minimal subepithelial flap availability for urethral suture line closure during the initial metoidioplasty. Therefore, the primary strategy for fistula repair is separation of the urethral epithelium from the phallus epithelium, with interposition of additional tissue. The urethral epithelium can be closed with inverting sutures followed by coverage with a dermal interposition graft, which can be harvested from the groin. The phallus skin is then closed over the graft. Proximal fistulas with often have dartos equivalent tissue for closure and don't require an interposition graft. Larger fistulas $(>5 \mathrm{~mm}$ ) may require an epidermal autograft from the groin or mouth depending on the fistula location to cover the defect. Urethras made from labia minora have mucosal like epithelium and may respond better to oral grafts; skin urethras from a neophallus respond about equally well to skin or oral grafts. Exceptionally large defects, or defects without sufficient neighboring vascularized tissue, may require a staged approach: the first stage is creation of a vascularized sufficiently wide urethral plate followed 6 months later by urethral tubularization.

Some patients desire urethral lengthening without vaginectomy. This is not a commonly desired surgery, but it frequently leads to urethrovaginal fistulas (62). Patients are counseled appropriately prior to undergoing this procedure and understand the expected need for fistula repair postoperatively. Treatment for this is similar to fistula repair at other urethral locations. The main difference is that definitive treatment may require vaginectomy, as this allows the development of local flaps to cover the urethrovaginal fistula repair site.

Strictures of the proximal labia minora urethra in metoidioplasty patients are frequently short and can be treated with anastomotic or Heineke-Mikulicz type repairs. 
Strictures associated with phalloplasty are commonly seen at the PF-PP anastomosis or distal urethra. Strategies for treatment are similar to strategies utilized for cismen urethroplasties: it depends on length and location of the strictures (65). Distal strictures with minimal scar tissue can be treated with staged Johanson urethroplasty or Asopa type urethroplasty $(56,66,67)$. Short PF-PP urethral strictures are amenable to anastomotic or HeinekeMikulicz urethroplasties (65); longer strictures require substitution urethroplasty with oral or skin grafts; long and obliterative strictures benefit from staged urethroplasties, and on rare occasion, a free flap urethroplasty (68-70). The appropriate timing of repair is usually about $3-4$ months from initial metoidioplasty or phalloplasty to allow tissue maturation and vascularization. For stricture recurrences after urethroplasty, 3-4 months is suggested prior to repeat urethroplasty. When patients have recurrences before the $3-4$ month period, SP tube urinary diversion is recommended until the appropriate time.

\section{Summary}

Gender related genitourinary surgeries are vitally important in the management of gender dysphoria. Vaginoplasty, metoidioplasty, phalloplasty and their associated surgeries help patients achieve their main goal of aligning their body and mind. These surgeries carry a significant risk as a large percentage of patients will require corrective surgeries from complications that arise. Despite this, there are more patients needing and wanting surgery than there are providers able to perform them. There is also a parallel and exponentially increasing need for patients to find capable care for postoperative issues that arise. Fortunately, there is a favorable trend towards more centers, health systems, and surgeons offering services for TGNC individuals.

\section{Acknowledgments}

None.

\section{Footnote}

Conflicts of Interest: The authors have no conflicts of interest to declare.

Ethical Statement: The authors are accountable for all aspects of the work in ensuring that questions related to the accuracy or integrity of any part of the work are appropriately investigated and resolved.

\section{References}

1. Zucker KJ. Epidemiology of gender dysphoria and transgender identity. Sex Health 2017;14:404-11.

2. Davydov SN. Colpopoeisis from the peritoneum of the uterorectal space. Akush Ginekol (Mosk) 1969;45:55-7.

3. Jiang DD, Gallagher S, Burchill L, et al. Implementation of a Pelvic Floor Physical Therapy Program for Transgender Women Undergoing Gender-Affirming Vaginoplasty. Obstet Gynecol 2019;133:1003-11.

4. Horbach SE, Bouman MB, Smit JM, et al. Outcome of vaginoplasty in male-to-female transgenders: a systematic review of surgical techniques. J Sex Med 2015;12:1499-512.

5. Jacoby A, Maliha S, Granieri M, et al. Robotic Davydov Peritoneal Flap Vaginoplasty for Augmentation of Vaginal Depth in Feminizing Vaginoplasty. J Urol 2019;201:1171-6.

6. van der Sluis WB, Bouman MB, Buncamper ME, et al. Clinical characteristics and management of neovaginal fistulas after vaginoplasty in transgender women. Obstet Gynecol 2016;127:1118-26.

7. Dreher PC, Edwards D, Hager S, et al. Complications of the neovagina in male-to-female transgender surgery: A systematic review and meta-analysis with discussion of management. Clin Anat 2018;31:191-9.

8. Hadj-Moussa M, Ohl D, Kuzon W. Feminizing Genital Confirmation Surgery, Sex Med Rev 2018;6:457-68.e2.

9. Reed HM. Aesthetic and functional male to female genital and perineal surgery: feminizing vaginoplasty. Semin Plast Surg 2011;25:163-74.

10. Rossi Neto R, Hintz F, Krege S, et al. Gender reassignment surgery--a 13 year review of surgical outcomes. Int Braz J Urol 2012;38:97-107.

11. Perovic SV, Stanojevic D, Djordjevic M. Vaginoplasty in male transsexuals using penile skin and a urethral flap. BJU Int 2000;86:843-50.

12. Krege S, Bex A, Lümmen G, et al. Male-to-female transsexualism: a technique, results and long-term followup in 66 patients. BJU Int 2001;88:396-402.

13. Karim RB, Hage J, Bouman F, et al. The importance of near total resection of the corpus spongiosum and total resection of the corpora cavernosa in the surgery of male to female transsexuals. Ann Plast Surg 1991;26:554-6.

14. Gaither TW, Awad MA, Osterberg EC, et al. Postoperative Complications following Primary Penile Inversion Vaginoplasty among 330 Male-to-Female Transgender Patients.J Urol 2018;199:760-5. 
15. Raigosa M, Avvedimento S, Yoon T, et al. Male-to-female genital reassignment surgery: a retrospective review of surgical technique and complications in 60 patients. J Sex Med 2015;12:1837-45.

16. Lindström D, Sadr Azodi O, Wladis A, et al. Effects of a perioperative smoking cessation intervention on postoperative complications: a randomized trial. Ann Surg 2008;248:739-45.

17. Pierre S, Rivera C, Le Maitre B, et al. Guidelines on smoking management during the perioperative period. Anaesth Crit Care Pain Med 2017;36:195-200.

18. Schmid M, Sood A, Campbell L, et al. Impact of smoking on perioperative outcomes after major surgery. Am J Surg 2015;210:221-9.e6.

19. Turan A, Mascha EJ, Roberman D, et al. Smoking and perioperative outcomes. Anesthesiology 2011;114:837-46.

20. Takamatsu A, Harashina T. Labial ring flap: a new flap for metaidoioplasty in female-to-male transsexuals. J Plast Reconstr Aesthet Surg 2009;62:318-25.

21. Cohanzad S. Extensive Metoidioplasty as a Technique Capable of Creating a Compatible Analogue to a Natural Penis in Female Transsexuals. Aesthetic Plast Surg 2016;40:130-8.

22. Djinovic RP. Metoidioplasty. Clin Plast Surg 2018;45:381-6.

23. Djordjevic ML, Bizic M, Stanojevic D, et al. Urethral Lengthening in metoidioplasty (female-to-male sex reassignment surgery) by combined buccal mucosa graft and labia minora flap. Urology 2009;74:349-53.

24. Djordjevic ML, Bizic MR. Comparison of two different methods for urethral lengthening in female to male (metoidioplasty) surgery. J Sex Med 2013;10:1431-8.

25. Djordjevic ML, Stanojevic D, Bizic M, et al. Metoidioplasty as a single stage sex reassignment surgery in female transsexuals: Belgrade experience. J Sex Med 2009;6:1306-13.

26. Perovic SV, Djordjevic ML. Metoidioplasty: a variant of phalloplasty in female transsexuals. BJU Int 2003;92:981-5.

27. Frey JD, Poudrier G, Chiodo MV, et al. A Systematic Review of Metoidioplasty and Radial Forearm Flap Phalloplasty in Female-to-male Transgender Genital Reconstruction: Is the "Ideal" Neophallus an Achievable Goal? Plast Reconstr Surg Glob Open 2016;4:e1131.

28. Xu KY, Watt AJ. The Pedicled Anterolateral Thigh Phalloplasty. Clin Plast Surg 2018;45:399-406.

29. Wirthmann AE, Majenka P, Kaufmann MC, et al. Phalloplasty in Female-to-Male Transsexuals by Gottlieb and Levine's Free Radial Forearm Flap Technique-A
Long-Term Single-Center Experience Over More than Two Decades. J Reconstr Microsurg 2018;34:235-41.

30. Schechter LS, Safa B. Introduction to Phalloplasty. Clin Plast Surg 2018;45:387-9.

31. van der Sluis WB, Smit JM, Pigot GLS, et al. Double flap phalloplasty in transgender men: Surgical technique and outcome of pedicled anterolateral thigh flap phalloplasty combined with radial forearm free flap urethral reconstruction. Microsurgery 2017;37:917-23.

32. Sarıkaya S, Ralph DJ. Mystery and realities of phalloplasty: a systematic review. Turk J Urol 2017;43:229-36.

33. D'Arpa S, Colebunders B, Stillaert F, et al. Pre-expanded Anterolateral Thigh Perforator Flap for Phalloplasty. Clin Plast Surg 2017;44:129-41.

34. Salgado CJ, Nugent AG, Moody AM, et al. Immediate pedicled gracilis flap in radial forearm flap phalloplasty for transgender male patients to reduce urinary fistula. J Plast Reconstr Aesthet Surg 2016;69:1551-7.

35. Morrison SD, Shakir A, Vyas KS, et al. Phalloplasty: A Review of Techniques and Outcomes. Plast Reconstr Surg 2016;138:594-615.

36. Garaffa G, Ralph DJ. Free Flap Phalloplasty For Female To Male Gender Dysphoria. J Sex Med 2016;13:1942-7.

37. Morrison SD, Son J, Song J, et al. Modification of the tube-in-tube pedicled anterolateral thigh flap for total phalloplasty: the mushroom flap. Ann Plast Surg 2014;72 Suppl 1:S22-6.

38. Hasegawa K, Namba Y, Kimata Y. Phalloplasty with an innervated island pedicled anterolateral thigh flap in a female-to-male transsexual. Acta Med Okayama 2014;68:183-90.

39. Garaffa G, Spilotros M, Christopher NA, et al. Total phallic reconstruction using radial artery based forearm free flap phalloplasty in patients with epispadias-exstrophy complex. J Urol 2014;192:814-20.

40. Bajpai M. "Bird-Wing" abdominal phalloplasty: A novel surgical technique for penile reconstruction. J Indian Assoc Pediatr Surg 2013;18:49-52.

41. Hakky TS, Rodriguez AR, Parker J, et al. Ventral phalloplasty. Int Braz J Urol 2012;38:565-6.

42. Bajpai M. Scrotal phalloplasty: A novel surgical technique for aphallia during infancy and childhood by pre-anal anterior coronal approach. J Indian Assoc Pediatr Surg 2012;17:162-4.

43. Kim SK, Lee KC, Kwon YS, et al. Phalloplasty using radial forearm osteocutaneous free flaps in female-to-male transsexuals. J Plast Reconstr Aesthet Surg 2009;62:309-17.

44. Perovic SV, Djinovic R, Bumbasirevic M, et al. Total phalloplasty using a musculocutaneous latissimus dorsi 
flap. BJU Int 2007;100:899-905; discussion 905.

45. Felici N, Felici A. A new phalloplasty technique: the free anterolateral thigh flap phalloplasty. J Plast Reconstr Aesthet Surg 2006;59:153-7.

46. Dabernig J, Chan LK, Schaff J. Phalloplasty with free (septocutaneous) fibular flap sine fibula. J Urol 2006;176:2085-8.

47. Bettocchi C, Ralph DJ, Pryor JP. Pedicled pubic phalloplasty in females with gender dysphoria. BJU Int 2005;95:120-4.

48. Zieliński T. Phalloplasty using a lateral groin flap in female-to-male transsexuals. Acta Chir Plast 1999;41:15-9.

49. Fang RH, Kao YS, Ma S, et al. Phalloplasty in female-tomale transsexuals using free radial osteocutaneous flap: a series of 22 cases. Br J Plast Surg 1999;52:217-22.

50. Hage JJ, Winters HA, Van Lieshout J. Fibula free flap phalloplasty: modifications and recommendations. Microsurgery 1996;17:358-65.

51. Hage JJ, Bloem JJ, Suliman HM. Review of the literature on techniques for phalloplasty with emphasis on the applicability in female-to-male transsexuals. J Urol 1993;150:1093-8.

52. Hage JJ. Phalloplasty techniques. J Reconstr Microsurg 1992;8:233-4.

53. Papadopulos NA, Schaff J, Biemer E. The use of free prelaminated and sensate osteofasciocutaneous fibular flap in phalloplasty. Injury 2008;39 Suppl 3:S62-7.

54. Caso J, Keating M, Miranda-Sousa A, et al. Ventral phalloplasty. Asian J Androl 2008;10:155-7.

55. Santucci RA. Urethral Complications After Transgender Phalloplasty: Strategies to Treat Them and Minimize Their Occurrence. Clin Anat 2018;31:187-90.

56. Remington AC, Morrison SD, Massie JP, et al. Outcomes after Phalloplasty: Do Transgender Patients and Multiple Urethral Procedures Carry a Higher Rate of Complication? Plast Reconstr Surg 2018;141:220e-9e.

57. Nikolavsky D, Hughes M, Zhao LC. Urologic Complications After Phalloplasty or Metoidioplasty. Clin Plast Surg 2018;45:425-35.

58. Esmonde N, Bluebond-Langner R, Berli JU. Phalloplasty Flap-Related Complication. Clin Plast Surg 2018;45:415-24.

59. Ascha M, Massie JP, Morrison SD, et al. Outcomes of Single Stage Phalloplasty by Pedicled Anterolateral Thigh Flap versus Radial Forearm Free Flap in Gender Confirming Surgery. J Urol 2018;199:206-14.
60. Terrier JÉ, Courtois F, Ruffion A, et al. Surgical outcomes and patients' satisfaction with suprapubic phalloplasty. J Sex Med 2014;11:288-98.

61. Gonzalez AC, Costa TF, Andrade ZA, et al. Wound healing - A literature review. An Bras Dermatol 2016;91:614-20.

62. Massie JP, Morrison SD, Wilson SC, et al. Phalloplasty with Urethral Lengthening: Addition of a Vascularized Bulbospongiosus Flap from Vaginectomy Reduces Postoperative Urethral Complications. Plast Reconstr Surg 2017;140:551e-8e.

63. Nikolavsky D, Yamaguchi Y, Levine JP, et al. Urologic Sequelae Following Phalloplasty in Transgendered Patients. Urol Clin North Am 2017;44:113-25.

64. Salgado CJ, Fein LA, Chim J, et al. Prelamination of Neourethra with Uterine Mucosa in Radial Forearm Osteocutaneous Free Flap Phalloplasty in the Femaleto-Male Transgender Patient. Case Rep Urol 2016;2016:8742531.

65. Lumen N, Monstrey S, Goessaert AS, et al. Urethroplasty for strictures after phallic reconstruction: a singleinstitution experience. Eur Urol 2011;60:150-8.

66. Pisapati VL, Paturi S, Bethu S, et al. Dorsal buccal mucosal graft urethroplasty for anterior urethral stricture by Asopa technique. Eur Urol 2009;56:201-5.

67. Marshall SD, Raup V'T, Brandes SB. Dorsal inlay buccal mucosal graft (Asopa) urethroplasty for anterior urethral stricture. Transl Androl Urol 2015;4:10-5.

68. Chauhan A, Sham E, Chee J. Microsurgical Urethroplasty for Complex Bulbar Urethral Strictures Using the Radial Forearm Free Flap Prelaminated with Buccal Mucosa. J Reconstr Microsurg 2016;32:378-85.

69. Khazanchi RK, Dorairajan LN, Dogra PN, et al. Freeflap urethroplasty for a complex, long-segment stricture of the bulbomembranous urethra. J Reconstr Microsurg 1998;14:223-5.

70. Tobelem G, Schrameck E, Arvis G. Urethral stricture: one-stage urethroplasty using a free skin flap. Presse Med 1984;13:2013-5.

Cite this article as: Chen ML, Reyblat P, Poh MM, Chi AC. Overview of surgical techniques in gender-affirming genital surgery. Transl Androl Urol 2019;8(3):191-208. doi: 10.21037/ tau.2019.06.19 